Note

\title{
Development of an allele-specific PCR for Escherichia coli B2 sub-typing, a rapid and easy to perform substitute of multilocus sequence typing
}

\author{
Olivier Clermont ${ }^{\mathrm{a}, \mathrm{b}}$, Julia K. Christenson ${ }^{\mathrm{c}}$, Anne-Sophie Daubié ${ }^{\mathrm{a}, \mathrm{d}}$, David M. Gordon ${ }^{\mathrm{c}}$, Erick Denamur ${ }^{\mathrm{a}, \mathrm{b}, *}$ \\ a INSERM, IAME, UMR 1137, F-75018 Paris, France \\ b Univ Paris Diderot, IAME, UMR 1137, Sorbonne Paris Cité, F-75018 Paris, France \\ c Division of Evolution, Ecology E Genetics, Research School of Biology, The Australian National University, Canberra ACT 0200, Australia \\ ${ }^{\mathrm{d}}$ Univ Paris Nord, IAME, UMR 1137, Sorbonne Paris Cité, F-75018 Paris, France
}

\section{A R T I C L E I N F O}

\section{Article history:}

Received 23 January 2014

Received in revised form 19 March 2014

Accepted 20 March 2014

Available online 28 March 2014

\section{Keywords:}

Escherichia coli

B2 phylogroup

B2 sub-group

Sequence type complex

Allele-specific PCR

\begin{abstract}
A B S T R A C T
We developed and validated an allele-specific PCR method for detecting the nine main Escherichia coli phylogroup B2 lineages involved in extra-intestinal infections, which could be used as a substitute for multilocus sequence typing in studies for which the greater resolution at the sequence type level is not needed.
\end{abstract}

(c) 2014 Elsevier B.V. All rights reserved.
Escherichia coli is not only a commensal of the gut of the vertebrates (Tenaillon et al., 2010) but also a major intestinal and extra-intestinal pathogen (Croxen and Finlay, 2010; Lefort et al., 2011). It has a strong clonal population structure (Selander and Levin, 1980; Desjardins et al., 1995), with the delineation of robust phylogenetic groups and sub-groups also called lineages or sequence type complexes (STc) (Jolley and Maiden, 2010) in reference to multi-locus sequence typing (MLST) (Lecointre et al., 1998; Reid et al., 2000; Wirth et al., 2006; Le Gall et al., 2007; Gordon et al., 2008; Jaureguy et al., 2008). One of the major E. coli phylogenetic groups is the B2 phylogroup. At least 10 phylogenetic sub-groups (I-X) or lineages, in addition to the enteropathogenic E. coli (EPEC)-1 lineage, have been identified in the B2 group (Le Gall et al., 2007). Recently, due to the increased use of MLST in epidemiologic analyses, it appears that some of these sub-groups are found preferentially in the various extra-intestinal pathologies (Bidet et al., 2007; Bert et al., 2010; Mahjoub-Messai et al., 2011; Bengtsson et al., 2012; Gibreel et al., 2012; Alhashash et al., 2013). Thus, identification of the clinically significant B2 sub-groups or STc is desirable. However, MLST is still a costly and time-consuming approach. There is clearly the need for the development of a rapid and easy to perform method that can be used world-wide in classical bacteriology laboratories

\footnotetext{
* Corresponding author at: INSERM U1137, Faculté de Médecine Paris Diderot, Site Xavier Bichat, 16 rue Henri Huchard, 75018 Paris, France. Tel.: +3315727 7739.

E-mail address: erick.denamur@inserm.fr (E. Denamur).
}

performing molecular typing. With these objectives in mind, we developed an allele-specific PCR method for detecting the main E. coli B2 STc.

Based on the literature (Bidet et al., 2007; Bert et al., 2010; Clermont et al., 2011; Mahjoub-Messai et al., 2011; Bengtsson et al., 2012; Gibreel et al., 2012; Alhashash et al., 2013), we decided to focus on the 9 previously reported sub-groups that have been found to be repeatedly involved in various extra-intestinal infections of humans, i.e. sub-groups I to VII, IX and X. So as to be easily recognized by the scientific community using the Achtman MLST scheme, we also named these 9 sub-groups or lineages as STc followed by the number of the most common [which is not always the most central genotype (Jolley and Maiden, 2010)] ST according to Achtman (http://mlst.ucc.ie/mlst/dbs/Ecoli).

We designed allele-specific primers that could amplify specific subgroup strains but not strains from the other sub-groups within the B2 group, using the nucleotide sequence alignments of the MLST data. These primers were also designed so that the PCR amplified products would give distinct resolvable fragment lengths. We thus decided to use 2 panels of primers, corresponding to 2 independent multiplex PCRs (Table 1). In the first panel, sub-groups II (STc73), III (STc127), VI (STc12), VII (STc14), and IX (STc95) are identified, whereas the second panel identifies sub-groups I (STc131), IV (STc141), V (STc144) and X (STc372) (Fig. 1). In both panels, we included primers for an internal control present in all B2 strains (chuA gene) that allow checking of the quality of the DNA. A band weaker than the control band should not be considered as positive. Each PCR reaction was 
Table 1

List of the primers used in the study and sizes of the PCR products.

\begin{tabular}{|c|c|c|c|c|}
\hline Primer designation & Primer sequences & Target & Sub-group & Size of PCR product (bp) \\
\hline \multicolumn{5}{|l|}{ Panel 1} \\
\hline pabBgplI.f & 5'-GAGTCACTGCCAGAAATTGCA-3' & $p a b B$ & II & 415 \\
\hline pabBgplI.r & 5'-GGCGAAAGGCTTAAAATTGCACT-3' & & & \\
\hline trpAgpIII.f & 5'-GACGCGCTGGAATTAGGCTC-3' & $\operatorname{trp} A$ & III & 255 \\
\hline trpAgpIII.r & 5'-ATCGGCAACCAGCACCGAAT-3' & & & \\
\hline dinBgpVI.f & 5'-CAGCGGTGGAGATGCGCGAT-3' & $\operatorname{din} B$ & VI & 652 \\
\hline dinBgpVI.r & 5'-TCGTCAATGCCCTGACTACA-3' & & & \\
\hline icdgpVII.f & 5'-GCGGTATTCGCTCTCTGAAT-3' & $i c d$ & VII & 810 \\
\hline icdgpVII.r & 5'-CAATTAAATCAGCCGCTTCG-3' & & & \\
\hline aesgpIX.f & 5'-CCTGGCCTGCAACGGGAG-3' & aes & IX & 160 \\
\hline aesgpIX.r & 5'-TCTGGCTGCGGATAAAAGAG-3' & & & \\
\hline chuAgene.1 & 5'-CGATACGGTCGATGCAAAAG-3' & chuA & Internal control & 1013 \\
\hline chuAgene.2 & 5'-TTGGACAACATCAGGTCATC-3' & & & \\
\hline \multicolumn{5}{|l|}{ Panel 2} \\
\hline putPgpl.f & 5'-GGTATCGCTTACTTTAACGG-3' & putP & I & 373 \\
\hline putPgpl.r & 5'-ACCACCGGACCAAACGCC-3' & & & \\
\hline trpAgpIV.f & 5'-TGCCAGTGGAAGAGTCCGCT-3' & $\operatorname{trp} A$ & IV & 261 \\
\hline trpAgpIV.r & 5'-CCGGGGCGGAAATACCAAAG-3' & & & \\
\hline polBgpV.f & 5'-GCCGTTTCGCCGAAGATAAA-3' & polB & V & 530 \\
\hline polBgpV.r & 5'-TAATGATCTTCAGCGCCTGT-3' & & & \\
\hline aesgpX.f & 5'-GACCGTTGTGAATACTCTTCA-3' & aes & $\mathrm{X}$ & 713 \\
\hline aesgpX.r & 5'-TATAACAGGGCGGCACATTT-3' & & & \\
\hline chuAgene.1 & 5'-CGATACGGTCGATGCAAAAG-3' & chuA & Internal control & 1013 \\
\hline chuAgene.2 & 5'-TTGGACAACATCAGGTCATC-3' & & & \\
\hline
\end{tabular}

A

Panel 1

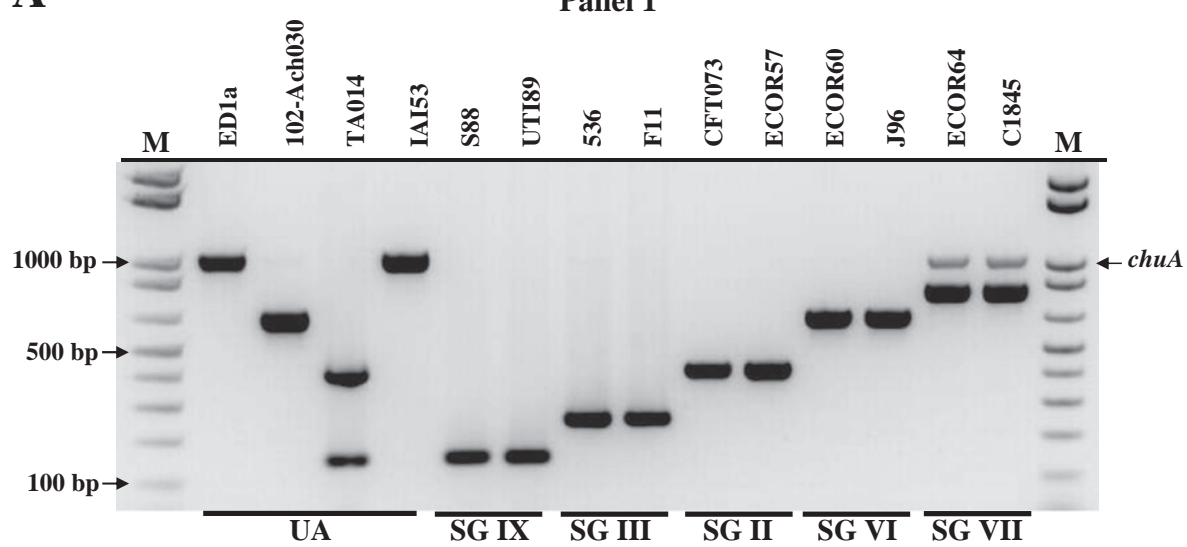

B

Panel 2

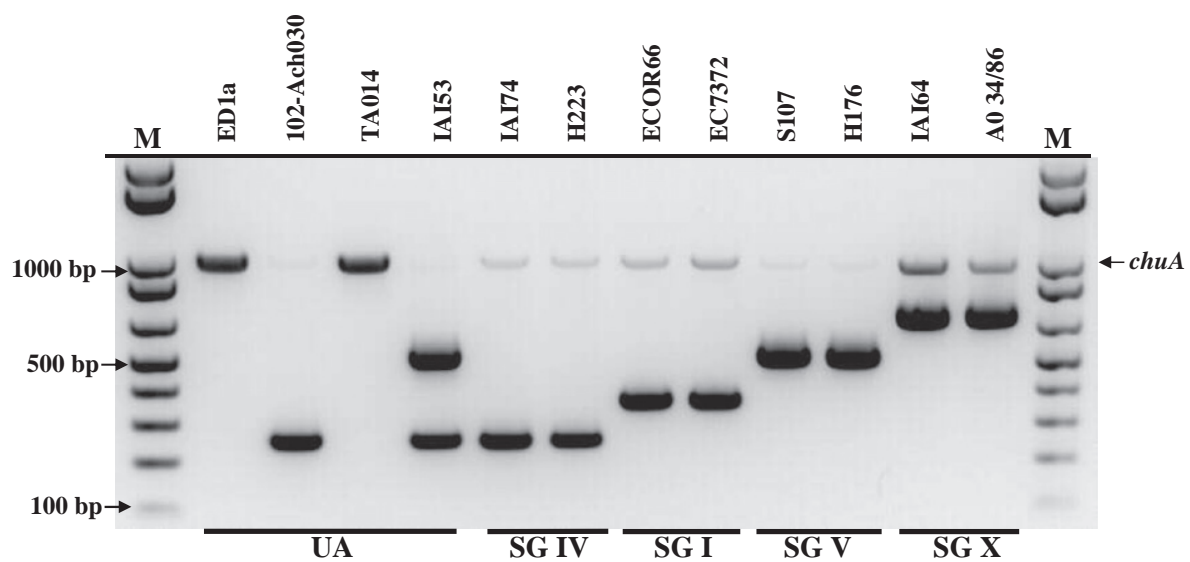

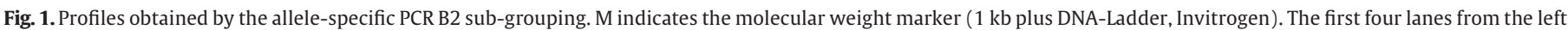

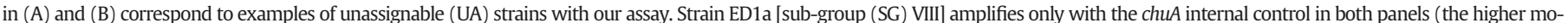

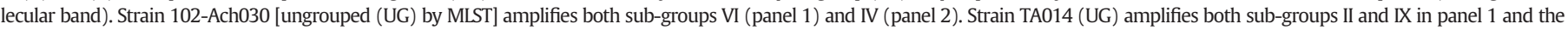

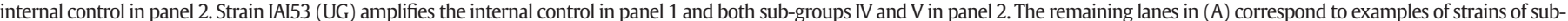

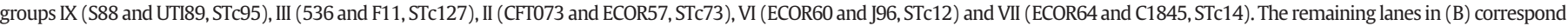

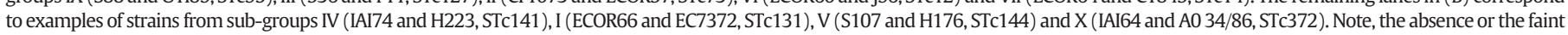
amplification of the internal control chuA (indicated by an arrow) is due to the competition between chuA and the allele-specific targets, the sizes of the latter being smaller. 
carried out in a $20-\mu \mathrm{l}$ volume containing $2 \mu \mathrm{l}$ of $10 \times$ buffer (supplied with Taq polymerase) giving a final $\mathrm{MgCl}_{2}$ concentration at $1.5 \mathrm{mM}$, 20 pmol of each primer, $200 \mu \mathrm{m}$ each dNTP, $2 \mathrm{U}$ of Taq polymerase (Promega, Charbonnières-les-Bains, France), and $3 \mu$ of bacterial lysate supernatant ( 10 colonies in $500 \mu$ of water boiled, chilled in ice and centrifuged) or $2 \mu$ of DNA (approximately $200 \mathrm{ng}$ ). PCR was performed with an Eppendorf Mastercycler with MicroAm tubes in the following conditions: 4 min denaturation at $94{ }^{\circ} \mathrm{C}, 30$ cycles for $5 \mathrm{~s}$ at $94{ }^{\circ} \mathrm{C}$ and $20 \mathrm{~s}$ at $63{ }^{\circ} \mathrm{C}$, and a final extension step of $5 \mathrm{~min}$ at $72{ }^{\circ} \mathrm{C}$. The primers used for panel 1 were: pabBgpII.f, pabBgpII.r, trpAgpIII.f, trpAgpIII.r, dinBgpVI.f, dinBgpVI.r, icdgpVII.f, icdgpVII.r, aesgpIX.f, aesgpIX.r, chuAgene. 1 and chuAgene.2. The primers used for panel 2 were: putPgpI.f, putPgpI.r, trpAgpIV.f, trpAgpIV.r, polBgpV.f, polBgpV.r, aesgpX.f, aesgpX.r, chuAgene.1 and chuAgene.2 (Table 1). The chuAgene. 1 and chuAgene. 2 primers amplify the chuA gene in all the B2 phylogroup strains (Clermont et al., 2013), which was used as an internal control. PCR products were loaded on $2 \%$ agarose gel with SYBR ${ }^{\circledR}$ Safe DNA gel stain (Invitrogen, Cergy Pontoise, France). After electrophoresis, the gels were photographed under UV light.

We considered strains as unassigned when (i) they only yielded a band for the chuA internal control or (ii) they gave 2 bands (excepting the chuA control) after screening with the two PCR panels. One hundred and fifty three E. coli phylogroup B2 strains belonging to several representative collections of $E$. coli isolated world-wide since the 1980 's from a variety of vertebrate species, and that include both fecal and clinical isolates (Ochman and Selander, 1984; Picard et al., 1999; Gordon and Cowling, 2003; Gordon et al., 2005; Clermont et al., 2011) and spanning the B2 ST diversity based on an extensive MLST (13 genes, 9807 nucleotides) were studied (Table S1 and Fig S1). The sensitivity of the assay was very good. All strains $(n=57)$ of sub-groups II, III, IV, V, VI, VII, IX and X were correctly assigned to their respective subgroups by our allele-specific PCR. For sub-group I strains, 5 of the twenty strains tested were unassigned: 2 strains did not give any PCR product except for the internal control (TA216 and B1098), 2 closely related strains (B103 and E2062) yielded PCR products corresponding to sub-groups $V$ and $X$, and one strain (M605) yielded sub-group I and X PCR products.

Inspection of the nucleotide sequence data revealed the reasons for the discrepancies observed between the MLST data and the PCR-based sub-typing method. Strain M605 not only exhibits the polymorphism in putP corresponding to sub-group I, but also has the sub-group $\mathrm{X}$ aes polymorphism, an outcome that probably represents a horizontal gene transfer event. Strain TA216 exhibits a putP allele of unknown origin, while strain B1098 exhibits a putP allele corresponding to sub-group IV. Horizontal gene transfer likely also explains the results for strains B103 and E2062, as these strains exhibit a putP allele corresponding to sub-group III and divergent alleles for the polB and aes genes. In fact, sub-group I is highly diverse and encompasses more STs than the classical ST131, which is already heterogeneous. Indeed, ST131 is composed at least of O25b (NA114 and EC7372) and 016 (SE15) clones (Matsumura et al., 2012; Dahbi et al., 2013; Johnson et al., 2014).

The 3 EPEC- 1 strains and the 3 sub-group VIII strains (Clermont et al., 2008), as expected, were unassignable with our PCR assay. Of the 70 strains that could not be assigned using the MLST data to subgroups I$\mathrm{X}$, that is the ungrouped strains, 61 were unassignable using PCR panels I and II. Among the 9 remaining strains, 3 strains closely related to subgroup IV, including the AIEC strain LF82, amplify with the primers that we have designed for targeting sub-group IV strains (Fig. S1). We were not able to find single nucleotide polymorphisms in the sequences that could discriminate between these two closely related groups of strains. This represents a limitation of our assay, but on another hand does allow these adherent-invasive $E$. coli (AIEC) strains to be identified. Six strains were mis-assigned to sub-groups II (1 strain), VII (1 strain), IX (3 strains) and X (1 strain). In all cases, we observed in the targeted sequences of $p a b B$, icd and aes the polymorphisms specific of sub-
Table 2

Sensitivity and specificity of the allele specific PCR assay for the B2 sub-grouping of E. coli.

\begin{tabular}{llclll}
\hline $\begin{array}{l}\text { B2 sub- } \\
\text { group }\end{array}$ & $\begin{array}{l}\text { STc designation } \\
\text { according to } \\
\text { Achtman } \\
\text { scheme }\end{array}$ & $\begin{array}{l}\text { No. of } \\
\text { tested } \\
\text { strains }\end{array}$ & $\begin{array}{l}\text { Specific } \\
\text { PCR-positive } \\
\text { strains }\end{array}$ & $\begin{array}{l}\text { Sensitivity } \\
(\%)\end{array}$ & $\begin{array}{l}\text { Specificity (false } \\
\text { positive/no of } \\
\text { tested strains) }\end{array}$ \\
\hline I & 131 & 28 & 23 & 82.1 & $0 / 215$ \\
II & 73 & 20 & 20 & 100 & $1 / 215$ \\
III & 127 & 11 & 11 & 100 & $0 / 215$ \\
IV & 141 & 10 & 10 & 100 & $3^{\mathrm{b}} / 215$ \\
V & 144 & 3 & 3 & 100 & $0 / 215$ \\
VI & 12 & 10 & 10 & 100 & $0 / 215$ \\
VII & 14 & 12 & 12 & 100 & $1 / 215$ \\
IX & 95 & 37 & 37 & 100 & $3 / 215$ \\
X & 372 & 5 & 5 & 100 & $1 / 215$ \\
Total & & 137 & 132 & 96.3 & $9 / 215$ \\
\hline
\end{tabular}

a Wirth et al. (2006).

b These 3 strains correspond to the group closely related to sub-group IV that encompasses the AIEC LF82 strain.

groups II, VII, IX and X, respectively, indicating the presence of horizontal gene transfer.

We also screened 62 B2 strains characterized using the Institut Pasteur MLST scheme (Jaureguy et al., 2008) and assigned using the MLST data to a sub-group: sub-group I $(n=8)$, sub-group II $(n=8)$, sub-group III ( $\mathrm{n}=8)$, sub-group IV $(\mathrm{n}=5)$, sub-group $\mathrm{V}(\mathrm{n}=1)$, sub-group VI $(n=3)$, sub-group VII $(n=7)$, sub-group VIII $(n=1)$, sub-group IX $(n=17)$, sub-group $X(n=2)$ and ungrouped $(n=2)$ strains. All strains belonging to sub-groups I to VII, IX and X were correctly assigned, whereas the sub-group VIII and the ungrouped strains, as expected, were unassignable. A summary of the sensitivity/specificity of our assay on all the tested strains is given in Table 2 .

Lastly, we characterized 283 B2 phylogroup bacteremia clinical isolates recovered from humans living in Australia and France using our sub-typing assay. Among the strains, only $4.9 \%$ were unassigned and the majority of the strains were found to belong to the IX (STc95) and II (STc73) sub-groups (28.2 and 27.9\%, respectively), followed by the sub-group I (STc131) strains (14.1\%). Strains belonging to all the other sub-groups were identified, but at a level below $10 \%$. Interestingly, the prevalence of the sub-groups was similar in both countries (Table S2).

We have developed a robust, rapid, easy to perform and non-costly assay that allows B2 strains responsible of human extra-intestinal infections to be accurately typed to the 9 main sub-groups or lineages. While we were focused on the detection of the sub-groups implicated in extraintestinal infections, our assay can be developed to identify additional sub-groups according to the epidemiological purpose.

Supplementary data to this article can be found online at http://dx. doi.org/10.1016/j.mimet.2014.03.008.

\section{References}

Alhashash, F., Weston, V., Diggle, M., McNally, A., 2013. Multidrug-resistant Escherichia coli bacteremia. Emerg. Infect. Dis. 19, 1699-1701.

Bengtsson, S., Naseer, U., Sundsfjord, A., Kahlmeter, G., Sundqvist, M., 2012. Sequence types and plasmid carriage of uropathogenic Escherichia coli devoid of phenotypically detectable resistance. J. Antimicrob. Chemother. 67, 69-73.

Bert, F., Johnson, J.R., Ouattara, B., Leflon-Guibout, V., Johnston, B., Marcon, E., Valla, D. Moreau, R., Nicolas-Chanoine, M.H., 2010. Genetic diversity and virulence profiles of Escherichia coli isolates causing spontaneous bacterial peritonitis and bacteremia in patients with cirrhosis. J. Clin. Microbiol. 48, 2709-2714.

Bidet, P., Mahjoub-Messai, F., Blanco, J., Dehem, M., Aujard, Y., Bingen, E., Bonacorsi, S. 2007. Combined multilocus sequence typing and O serogrouping distinguishes Escherichia coli subtypes associated with infant urosepsis and/or meningitis. J. Infect. Dis. 196, 297-303.

Clermont, O., Lescat, M., O'Brien, C.L., Gordon, D.M., Tenaillon, O., Denamur, E., 2008 Evidence for a human-specific Escherichia coli clone. Environ. Microbiol. 10, 1000-1006.

Clermont, O., Olier, M., Hoede, C., et al., 2011. Animal and human pathogenic Escherichia coli strains share common genetic backgrounds. Infect. Genet. Evol. 11, 654-662.

Clermont, O., Christenson, J.K., Denamur, E., Gordon, D.M., 2013. The Clermont Escherichia coli phylo-typing method revisited: improvement of specificity and detection of new phylo-groups. Environ. Microbiol. Rep. 8, 58-65. 
Croxen, M.A., Finlay, B.B., 2010. Molecular mechanisms of Escherichia coli pathogenicity. Nat. Rev. Microbiol. 8, 26-38.

Dahbi, G., Mora, A., Lopez, C., et al., 2013. Emergence of new variants of ST131 clonal group among extraintestinal pathogenic Escherichia coli producing extendedspectrum beta-lactamases. Int. J. Antimicrob. Agents 42, 347-351.

Desjardins, P., Picard, B., Kaltenbock, B., Elion, J., Denamur, E., 1995. Sex in Escherichia coli does not disrupt the clonal structure of the population: evidence from random amplified polymorphic DNA and restriction-fragment-length polymorphism. J. Mol. Evol. 41, 440-448.

Gibreel, T.M., Dodgson, A.R., Cheesbrough, J., Fox, A.J., Bolton, F.J., Upton, M., 2012. Population structure, virulence potential and antibiotic susceptibility of uropathogenic Escherichia coli from Northwest England. J. Antimicrob. Chemother. 67, 346-356.

Gordon, D.M., Cowling, A., 2003. The distribution and genetic structure of Escherichia coli in Australian vertebrates: host and geographic effects. Microbiology 149 3575-3586.

Gordon, D.M., Stern, S.E., Collignon, P.J., 2005. Influence of the age and sex of human hosts on the distribution of Escherichia coli ECOR groups and virulence traits. Microbiology 151, 15-23.

Gordon, D.M., Clermont, O., Tolley, H., Denamur, E., 2008. Assigning Escherichia coli strains to phylogenetic groups: multi-locus sequence typing versus the PCR triplex method. Environ. Microbiol. 10, 2484-2496.

Jaureguy, F., Landreau, L., Passet, V., et al., 2008. Phylogenetic and genomic diversity of human bacteremic Escherichia coli strains. BMC Genomics 9, 560.

Johnson, J.R., Clermont, O., Johnston, B., Clabots, C., Tchesnokova, V., Sokurenko, E., Junka, A.F., Maczynska, B., Denamur, E., 2014. Rapid and specific detection, molecular epidemiology, and experimental virulence of the 016 subgroup within Escherichia coli sequence type 131. J. Clin. Microbiol. http://dx.doi.org/10.1128/JCM.03502-13 (early edition).

Jolley, K.A., Maiden, M.C., 2010. BIGSdb: scalable analysis of bacterial genome variation at the population level. BMC Bioinforma. 11, 595

Le Gall, T., Clermont, O., Gouriou, S., Picard, B., Nassif, X., Denamur, E., Tenaillon, O., 2007. Extraintestinal virulence is a coincidental by-product of commensalism in B2 phylogenetic group Escherichia coli strains. Mol. Biol. Evol. 24, 2373-2384.
Lecointre, G., Rachdi, L., Darlu, P., Denamur, E., 1998. Escherichia coli molecular phylogeny using the incongruence length difference test. Mol. Biol. Evol. 15, 1685-1695.

Lefort, A., Panhard, X., Clermont, O., Woerther, P.L., Branger, C., Mentre, F., Fantin, B., Wolff, M., Denamur, E., 2011. Host factors and portal of entry outweigh bacterial determinants to predict the severity of Escherichia coli bacteremia. J. Clin. Microbiol. 49, 777-783.

Mahjoub-Messai, F., Bidet, P. Caro, V., Diancourt, L, Biran, V., Aujard, Y, Bingen, E. Bonacorsi, S., 2011. Escherichia coli isolates causing bacteremia via gut translocation and urinary tract infection in young infants exhibit different virulence genotypes. J. Infect. Dis. 203, 1844-1849.

Matsumura, Y., Yamamoto, M., Nagao, M., Hotta, G., Matsushima, A., Ito, Y., Takakura, S, Ichiyama, S., 2012. Emergence and spread of B2-ST131-O25b, B2-ST131-016 and D-ST405 clonal groups among extended-spectrum-beta-lactamase-producing Escherichia coli in Japan. J. Antimicrob. Chemother. 67, 2612-2620.

Nei, M., Kumar, S., 2000. Molecular Evolution and Phylogenetics. Oxford University Press, New York.

Ochman, H., Selander, R.K., 1984. Standard reference strains of Escherichia coli from natural populations. J. Bacteriol. 157, 690-693.

Picard, B., Garcia, J.S., Gouriou, S., Duriez, P., Brahimi, N., Bingen, E., Elion, J., Denamur, E., 1999. The link between phylogeny and virulence in Escherichia coli extraintestinal infection. Infect. Immun. 67, 546-553.

Reid, S.D., Herbelin, C.J., Bumbaugh, A.C., Selander, R.K., Whittam, T.S., 2000. Parallel evolution of virulence in pathogenic Escherichia coli. Nature 406, 64-67.

Selander, R.K., Levin, B.R., 1980. Genetic diversity and structure in Escherichia coli populations. Science 210, 545-547.

Tamura, K., Peterson, D., Peterson, N., Stecher, G., Nei, M., Kumar, S., 2011. MEGA5: molecular evolutionary genetics analysis using maximum likelihood, evolutionary distance, and maximum parsimony methods. Mol. Biol. Evol. 28, 2731-2739.

Tenaillon, O., Skurnik, D., Picard, B., Denamur, E., 2010. The population genetics of commensal Escherichia coli. Nat. Rev. Microbiol. 8, 207-217.

Wirth, T., Falush, D., Lan, R., et al., 2006. Sex and virulence in Escherichia coli: an evolutionary perspective. Mol. Microbiol. 60, 1136-1151. 